\title{
Farinha de minhoca em dietas para juvenis de jundiá ${ }^{1}$
}

\author{
Patrícia Inês Mombach², Dirleise Pianesso², \\ Taida Juliana Adorian², Juliano Uczay ${ }^{3}$, Rafael Lazzari ${ }^{3}$
}

\begin{abstract}
Earthworm meal in jundiá juveniles diets

One of the greatest demands, concerning native fish nutrition, is the evaluation of alternative protein sources that can be used in diets. This study aimed at evaluating the growth rate and body composition of jundiá juveniles fed with different levels of earthworm meal. A total of 300 fish, with an average initial weight of $15.6 \mathrm{~g} \pm 5.65 \mathrm{~g}$, were distributed in 15 polypropylene tanks $(250 \mathrm{~L})$, for 30 days. A completely randomized design with five treatments $(10 \%, 20 \%, 30 \%$ and $40 \%$ of earthworm meal inclusion and a control treatment) and three replications, totaling 20 fish per experimental unit, was used. The fish were fed twice a day, getting $5 \%$ of their body weight in feed day $^{-1}$. At the end of the experimental period, the final weight, total and standard length, specific growth rate, condition factor and relative weight gain were evaluated. The body composition was also analyzed, being determined the rates of moisture, ashes and body fat and protein, as well as blood glucose. The weight and total and standard length were not influenced by the addition of earthworm meal to the diet. The inclusion levels of earthworm meal affected the fish specific growth rate, relative weight gain and condition factor. The earthworm meal can be added up to $30 \%$, in jundiá juveniles diets, without compromising fish growth.
\end{abstract}

KEY-WORDS: Rhamdia quelen (Quoy \& Gaimard, 1824); alternative protein source; fish nutrition.

\section{INTRODUÇÃO}

O pescado consumido no Brasil é, em sua maioria, oriundo da pesca extrativista, na qual se tem registrado incremento anual na produção de $2-5 \%$. Em 2010, a aquicultura nacional e a continental e marinha fecharam em alta, em relação a 2009, com acréscimo de $16,9 \%$ e $9 \%$, respectivamente, o que demonstra o potencial brasileiro para a produção de peixes em criatórios (Brasil 2012).

\section{RESUMO}

Uma das demandas, na nutrição de peixes nativos, é a avaliação de fontes proteicas alternativas, que possam ser utilizadas em dietas. Este trabalho objetivou avaliar o crescimento e a composição corporal de juvenis de jundiá submetidos a dietas com diferentes níveis de farinha de minhoca. Um total de 300 exemplares, com massa inicial média de 15,6 \pm 5,65 g, foram distribuídos em 15 tanques de polipropileno $(250 \mathrm{~L})$, durante 30 dias. O delineamento foi inteiramente casualizado, composto por cinco tratamentos $(10 \%, 20 \%, 30 \%$ e $40 \%$ de inclusão de farinha de minhoca e uma dieta controle) e três repetições, com 20 peixes por unidade experimental. Os peixes foram alimentados duas vezes ao dia, recebendo $5 \%$ do seu peso vivo em ração dia ${ }^{-1}$. Ao final do período experimental, foram avaliados a massa final, comprimento total e padrão, taxa de crescimento específico, fator de condição e ganho em massa relativo. Também foi realizada análise de composição corporal, sendo determinadas a umidade, cinzas e gordura e proteína corporal, além da glicose sanguínea. Para a massa e comprimento total e padrão, não houve influência da adição de farinha de minhoca na dieta. Os níveis de inclusão de farinha de minhoca influenciaram a taxa de crescimento específico, ganho em massa relativo e o fator de condição dos peixes. A farinha de minhoca pode ser incluída em até $30 \%$, na dieta de juvenis de jundiá, sem comprometer o crescimento dos peixes.

PALAVRAS-CHAVE: Rhamdia quelen (Quoy \& Gaimard, $1824)$; fonte proteica alternativa; nutrição de peixes.

$\mathrm{Na}$ piscicultura nacional, muitas espécies nativas apresentam potencialidade para criação. Entre elas, está o jundiá [Rhamdia quelen (Quoy \& Gaimard, 1824)], peixe com grande aceitação pelo mercado consumidor, devido à sua carne saborosa $\mathrm{e}$ ausência de espinhos intramusculares (Fracalossi et al. 2004). Os adultos desta espécie são onívoros e, no ambiente natural, se alimentam de peixes, crustáceos, insetos, restos vegetais e detritos orgânicos (Baldisserotto et al. 2010).

1. Trabalho recebido em jun./2013 e aceito para publicação em abr./2014 (nº registro: PAT 24569).

2. Universidade Federal de Santa Maria (UFSM), Departamento de Zootecnia, Santa Maria, RS, Brasil.

E-mails: patimombach@hotmail.com,dinapianesso@hotmail.com,tj.adorian@hotmail.com.

3. Universidade Federal de Santa Maria (UFSM), Departamento de Zootecnia e Ciências Biológicas, Palmeira das Missões, RS, Brasil.E-mails: uczay@ufsm.br, rlazzari@ufsm.br. 
A eficiência econômica é condição básica para a existência da atividade aquícola, sendo o custo da ração fator determinante na escolha, pelo aquicultor. O impacto do custo da ração sobre o resultado econômico da produção é dependente da associação entre os índices zootécnicos e econômicos (Souza et al. 2011).

A farinha de pescado é a fonte proteica mais utilizada em dietas para peixes (Pezzatto et al. 2002), porém, é um alimento de alto custo, que onera, significativamente, os sistemas aquícolas (Souza et al. 2004). A substituição da farinha de peixe de origem marinha por subprodutos de origem animal é uma das formas de se reduzir o custo da produção de organismos aquáticos (Millamena 2002).

Devido a um bom perfil de aminoácidos e aos minerais disponíveis nos produtos de origem animal, recomenda-se, para a dieta da maioria das espécies de peixes, principalmente nas fases iniciais, que parte da proteína seja de origem animal, para que sejam obtidos índices de desempenho satisfatórios (Galdioli et al. 2000). Para o jundiá, o uso de farinha de carne e ossos, combinada com farelo de soja, na dieta, tem se mostrado eficiente (Lazzari et al. 2008).

Crescentes preocupações relacionadas à preservação ambiental têm estimulado o desenvolvimento da vermicompostagem. Este fato, aliado ao rápido desenvolvimento de algumas espécies de minhoca, dentre elas a Eisenia foetida, tem possibilitado o uso destas para a fabricação de farinhas. Por caracterizar-se como alta fonte proteica - entre $68 \%$ e $82 \%$ de PB, conforme o tipo de alimentação fornecida à minhoca (Ferruzzi 2001) e apresentar perfil de ácidos graxos semelhante ao encontrado em peixes, a farinha de minhoca vem sendo utilizada como matéria-prima na formulação de rações para peixes e outros animais (Rotta et al. 2003).

Assim, este trabalho objetivou avaliar o crescimento e a composição corporal de juvenis de jundiá submetidos a dietas com diferentes níveis de farinha de minhoca.

\section{MATERIAL E MÉTODOS}

O experimento foi conduzido no Laboratório de Piscicultura da Universidade Federal de Santa Maria (UFSM), Campus de Palmeira das Missões (RS) (275' 58'S, 5318'49' W e 639 m de altitude), com duração de 30 dias, entre fevereiro e março de
2011, e todos os procedimentos estiveram de acordo com as normas éticas de bem-estar animal (parecer favorável do Comitê de Ética no Uso de Animais, n. 058/2011/UFSM-RS).

Foram utilizados 15 tanques de polipropileno (250 L), em um sistema com recirculação de água, filtragem biológica, entrada e saída individual de água, em cada unidade experimental, e abastecimento por meio de torneiras.

Utilizaram-se 300 juvenis de jundiá, sendo 20 animais/ unidade experimental, com massa inicial média de 15,6 $\pm 5,65 \mathrm{~g}$, que foram acondicionados no sistema de criação e passaram por um período de adaptação de sete dias, antes do início do experimento, o qual foi composto por cinco tratamentos, sendo quatro níveis de inclusão $(10 \%, 20 \%, 30 \%$ e $40 \%$ ) de farinha de minhoca $\left(\operatorname{Promin}^{\circledR}\right)$ na dieta e um tratamento controle (FM 0) (Tabela 1).

Para o preparo das dietas experimentais, os ingredientes foram pesados e misturados, com o auxílio de amassadeira industrial, até completa homogeneização, e, em seguida, adicionou-se água, até a massa atingir ponto adequado para peletização. Após a peletização, as dietas foram levadas a estufa de circulação forçada de ar, a $55^{\circ} \mathrm{C}$, por 24 horas. Após a secagem, as rações foram moídas e peneiradas, para a obtenção de grânulos de tamanho adequado para os peixes.

Diariamente, foram fornecidos aos peixes $5 \%$ de sua massa viva em ração, divididos em duas refeições, às $9 \mathrm{~h}$ e $17 \mathrm{~h}$. Pela manhã, antes da alimentação, retiravam-se todos os resíduos do dia anterior, por meio de sifonagem, e, em seguida, renovava-se, aproximadamente, $10 \%$ da água do sistema de recirculação. Semanalmente, realizava-se a determinação da biomassa total, com os peixes de cada tanque sendo capturados e pesados, com o objetivo de ajustar a quantidade de ração a ser fornecida.

O controle de qualidade da água foi realizado por meio de limpezas periódicas dos encanamentos, sifonagem dos resíduos e controle das variáveis físico-químicas da água, sendo analisados, diariamente, a temperatura (manhã e tarde), amônia total, nitrito e oxigênio dissolvido, e, semanalmente, a dureza, alcalinidade e $\mathrm{pH}$. Para a aferição da temperatura, foi utilizado um termômetro com bulbo de mercúrio e, para as demais análises, um kit colorimétrico marca Alfa-Tecnoquímica ${ }^{\circledR}$. A água para a realização das análises era coletada na entrada do filtro biológico, antes da sifonagem diária. 
Tabela 1. Composição das dietas experimentais (Palmeira das Missões, RS, 2011).

\begin{tabular}{|c|c|c|c|c|c|}
\hline \multirow{2}{*}{ Ingrediente } & \multicolumn{5}{|c|}{ Dieta $^{1}$} \\
\hline & FM0 & FM10 & FM20 & FM30 & FM40 \\
\hline Farelo de soja & 30 & 30 & 30 & 30 & 24,5 \\
\hline Farinha de minhoca & 0 & 10 & 20 & 30 & 40 \\
\hline Farinha de carne e ossos & 48 & 35 & 22 & 9 & 0 \\
\hline Farelo de trigo & 1 & 5 & 9,5 & 14 & 19 \\
\hline Milho moído & 12 & 12 & 12 & 12 & 12,5 \\
\hline Óleo de soja & 6 & 5 & 3,5 & 2 & 1 \\
\hline Vitaminas e minerais $^{2}$ & 1 & 1 & 1 & 1 & 1 \\
\hline Fosfato bicálcico & 1 & 1 & 1 & 1 & 1 \\
\hline \multirow[t]{2}{*}{ Sal } & 1 & 1 & 1 & 1 & 1 \\
\hline & \multicolumn{5}{|c|}{ Composição $^{3}$} \\
\hline Umidade & 6,86 & 9,62 & 10,08 & 9,74 & 7,90 \\
\hline Proteína & 45,77 & 44,44 & 42,43 & 40,31 & 40,70 \\
\hline Lipídios & 13,78 & 11,56 & 9,43 & 8,13 & 7,27 \\
\hline Cinzas & 12,14 & 10,86 & 9,61 & 8,50 & 7,96 \\
\hline Lisina & 2,24 & 2,65 & 3,07 & 3,48 & 3,86 \\
\hline Metionina & 0,61 & 0,73 & 0,85 & 0,97 & 1,09 \\
\hline Lisina/ Metionina & 3,67 & 3,63 & 3,61 & 3,58 & 3,54 \\
\hline Metionina + Cistina & 0,84 & 0,97 & 1,11 & 1,24 & 1,35 \\
\hline Treonina & 1,40 & 1,72 & 2,04 & 2,36 & 2,66 \\
\hline Triptofano & 0,38 & 0,48 & 0,58 & 0,68 & 0,77 \\
\hline Valina & 1,77 & 2,02 & 2,26 & 2,51 & 2,73 \\
\hline Isoleucina & 1,44 & 1,72 & 2,01 & 2,29 & 2,53 \\
\hline Leucina & 2,68 & 3,07 & 3,47 & 3,86 & 4,20 \\
\hline Fenilalanina & 1,56 & 1,77 & 1,98 & 2,19 & 2,35 \\
\hline Histidina & 0,89 & 1,03 & 1,17 & 1,31 & 1,43 \\
\hline Arginina & 2,79 & 3,01 & 3,24 & 3,47 & 3,67 \\
\hline
\end{tabular}

${ }^{1}$ Níveis de inclusão de farinha de minhoca (FM) na dieta (\%); ${ }^{2}$ Composição da mistura vitamínica (kg de produto/MigPlus): ácidos fólico: 1.200 mg, nicotínico: 24.000 mg e pantotênico: $12.000 \mathrm{mg}$; biotina: $48 \mathrm{mg}$; vitaminas A: $1.200 .000 \mathrm{UI}, \mathrm{B} 1: 4.800 \mathrm{mg}$, B2: $4.800 \mathrm{mg}$, B6: $4.800 \mathrm{mg}, \mathrm{B} 12: 4.800 \mathrm{mcg}$, C: $48 \mathrm{~g}, \mathrm{D} 3: 200.000 \mathrm{UI}, \mathrm{E}: 12.000 \mathrm{mg}$ e K3: 2400 mg. Composição da mistura mineral (kg de produto/MigPlus): Co: 10 mg; Cu: 3.000 mg; Fe: 50.000 mg; I: 100 mg; Mn: 20.000 mg; Se: 100 mg; e Zn: 3.000 mg. ${ }^{3}$ Valores de umidade, proteína, lipídios e cinzas foram analisados e valores de aminoácidos foram estimados segundo Rostagno et al. (2011), USA (2011) e perfil aminoacídico da farinha de minhoca fornecido pelo fabricante.

Foram realizadas duas biometrias: uma no início e a outra ao final do período experimental (30 dias). Para a realização destas, os peixes passaram por jejum de 12 horas, sendo, posteriormente, submetidos a sedação, utilizando-se o anestésico eugenol diluído em água (concentração de 0,02\%). Nestas biometrias, os peixes foram pesados e medidos individualmente. Na determinação da biomassa total (realizada semanalmente), os peixes de cada unidade experimental eram capturados e pesados todos juntos (sem medições individuais), a fim de ajustar a quantidade de ração a ser fornecida.

Os dados obtidos a partir das biometrias foram: peso (g), utilizando-se balança digital com duas casas decimais; e comprimento total $(\mathrm{cm})$ e padrão $(\mathrm{cm})$, medidos com o auxílio de ictiômetro graduado. Ao final do período experimental, também foram estimados a taxa de crescimento específico (TCE) $\left(\% \mathrm{dia}^{-1}\right)=\{[\ln ($ massa final $)-\ln ($ massa inicial $)] /$ $\operatorname{dias}\} * 100$; o ganho em massa relativo $(\mathrm{GMR})(\mathrm{g})=$ [(massa final - massa inicial)/massa inicial $] * 100$; e o fator de condição $(\mathrm{FC})=($ massa $* 100) /($ comprimento total ${ }^{3}$ ).

Para as análises de composição centesimal do peixe inteiro, foram abatidos 10 exemplares de cada tratamento, por meio de hipotermia, ao final do período experimental. A proteína bruta $(\mathrm{N} x 6,25)$ foi determinada pelo método de micro Kjeldahl (método 960.52) da AOAC (1995); a umidade pela perda de massa após 4 horas a $60^{\circ} \mathrm{C}$, em estufa com circulação forçada de ar, seguida de 8 horas a $105^{\circ} \mathrm{C}$; o conteúdo de cinzas a $550^{\circ} \mathrm{C}$ (método 923.03), de acordo com AOAC (1995); e a gordura seguindo-se o método de Bligh \& Dyer (1959).

Aos 30 dias de experimento, coletou-se sangue de quatro exemplares de cada tratamento, por 
punção na veia caudal, e, imediatamente, realizou-se a leitura da glicose, com aparelho medidor portátil (Accu-check Active ${ }^{\circledR}$ ).

O delineamento experimental utilizado foi o inteiramente ao acaso, com cinco tratamentos e três repetições, totalizando 15 unidades experimentais. Os dados obtidos foram submetidos a testes de normalidade (Shapiro-Wilk) e, como apresentaram distribuição normal, os valores foram analisados por regressão polinomial. Também foi realizada análise de covariância para as variáveis TCE e GMR, utilizando-se o valor proteico da ração como covariável. Os dados foram analisados com o auxílio do software Statistical Analysis System ${ }^{\circledR}$.

\section{RESULTADOS E DISCUSSÃO}

Os valores médios dos parâmetros físico-químicos de qualidade da água e seus respectivos desvios-padrões, observados durante o período experimental, foram os seguintes: $\mathrm{pH}=6,8 \pm$ 1,03 ; temperatura pela manhã $=22,73 \pm 1,54^{\circ} \mathrm{C}$; temperatura pela tarde $=23,8 \pm 1,13^{\circ} \mathrm{C}$; oxigênio dissolvido $=2,88 \pm 0,25 \mathrm{mg} \mathrm{L}^{-1}$; amônia total $=$ $0,54 \pm 0,56 \mathrm{mg} \mathrm{L}^{-1}$; nitrito $=0,05 \pm 0,04 \mathrm{mg} \mathrm{L}^{-1}$; alcalinidade $=32 \pm 11,66 \mathrm{mg} \mathrm{CaCO}_{3} \mathrm{~L}^{-1}$; dureza $=$ $85 \pm 28,86 \mathrm{mg} \mathrm{CaCO}_{3} \mathrm{~L}^{-1}$. Os parâmetros avaliados mantiveram-se dentro dos níveis aceitáveis para a criação da espécie, de acordo com Baldisserotto et al. (2010).

Apesar de a média dos níveis de oxigênio ter se mantido abaixo de $5 \mathrm{mg} \mathrm{L}^{-1}$, não foram observados sintomas de anóxia nos peixes ou mortes. Este fato é corroborado pelas taxas de crescimento apresentadas pelos peixes do presente trabalho, em relação a outros trabalhos com a espécie.

Quanto às variáveis de desempenho avaliadas (Tabela 2), não se observou efeito da inclusão de farinha de minhoca na dieta sobre a massa final e comprimento total e padrão $(\mathrm{p}<0,05)$.

Diferentemente dos resultados deste estudo, Rotta et al. (2003) verificaram, em pós-larvas de tilápias, que o nível de $20 \%$ de farinha de minhoca na dieta promoveu maior ganho em massa. Da mesma forma, para juvenis de carpa (Cyprinus carpio), este mesmo nível de substituição proporcionou melhora nos parâmetros de crescimento e, consequentemente, maiores valores de massa média final, taxa de eficiência proteica e de crescimento específico e menor valor de conversão alimentar (Rawling et al. 2012). Porém, estes mesmos autores também relataram menor número de leucócitos no sangue, quando a farinha de minhoca foi fornecida na dieta, necessitando-se, assim, averiguar como níveis inferiores a $20 \%$ de inclusão deste ingrediente afetam a saúde dos peixes.

Para juvenis de Heteroclarias, a substituição de $50 \%$ de farinha de peixe pela farinha de minhoca proporcionou melhoras nos parâmetros de crescimento e na taxa de eficiência proteica (Olele 2011). O mesmo aconteceu para juvenis de Heterobranchus longifilis, em que a farinha de minhoca substituiu, eficientemente, $50 \%$ da farinha de peixe (Sogbesan \& Madu 2008). Estes relatos confirmam que a farinha de minhoca pode ser incluída em dietas para peixes.

Para taxa de crescimento específico (TCE) e ganho em massa relativo (GMR), os jundiás alimentados com até $30 \%$ de farinha de minhoca apresentaram valores maiores, em relação aos submetidos a $40 \%$ de farinha de minhoca (Tabela 2). Estes resultados indicam que, para juvenis de jundiá, serão obtidos melhores valores para TCE e GMR, quando houver $25-30 \%$ de inclusão de farinha de minhoca na dieta.

A TCE é um índice utilizado para avaliar o crescimento de peixes jovens, em curto período de tempo (Baldisserotto 2009). Jundiás submetidos a diferentes fontes proteicas, na fase de recria, apresen-

Tabela 2. Desempenho de jundiás submetidos a alimentação com diferentes níveis de farinha de minhoca na dieta (Palmeira das Missões, RS, 2011).

\begin{tabular}{|c|c|c|c|c|c|c|}
\hline \multirow{2}{*}{ Variável } & \multicolumn{5}{|c|}{ Inclusão de farinha de minhoca (\%) } & \multirow[b]{2}{*}{$\mathrm{P}$} \\
\hline & 0 & 10 & 20 & 30 & 40 & \\
\hline Massa inicial (g) & $13,02 \pm 2,3$ & $13,98 \pm 2,2$ & $14,72 \pm 3$ & $14,20 \pm 2,1$ & $14,85 \pm 2,8$ & ns \\
\hline Massa final (g) & $25,11 \pm 4,4$ & $30,46 \pm 4$ & $33,26 \pm 8,5$ & $33,48 \pm 4,8$ & $28,03 \pm 7,5$ & ns \\
\hline Comprimento total $(\mathrm{cm})$ & $14,26 \pm 0,8$ & $14,59 \pm 0,8$ & $14,85 \pm 1,5$ & $14,85 \pm 0,6$ & $14,32 \pm 1,4$ & ns \\
\hline Comprimento padrão (cm) & $11,68 \pm 0,7$ & $11,95 \pm 0,7$ & $12,21 \pm 1,2$ & $12,22 \pm 0,5$ & $11,74 \pm 1,2$ & ns \\
\hline Taxa de crescimento específico $\left(\% \mathrm{dia}^{-1}\right)$ & $2,08 \pm 0,3 \mathrm{ab}$ & $2,54 \pm 0,2 \mathrm{ab}$ & $2,69 \pm 0,2 \mathrm{ab}$ & $2,94 \pm 0,3 \mathrm{a}$ & $2,15 \pm 0,3 b$ & $*$ \\
\hline Ganho em massa relativo $\left(\mathrm{g} \mathrm{dia}^{-1}\right)$ & $86,70 \pm 23 \mathrm{ab}$ & $115,18 \pm 16,3 \mathrm{ab}$ & $125,69 \pm 12 \mathrm{ab}$ & $141,23 \pm 19,7 \mathrm{a}$ & $91,20 \pm 17,7 b$ & $*$ \\
\hline
\end{tabular}

Médias seguidas por letras diferentes, na linha, apresentam diferença significativa, pelo teste de Pdiff (p $<0,05)$. * significativo a $5 \%$; ns: não significativo. 
taram melhor TCE, quando alimentados com dietas contendo farinha de peixe + farelo de soja $(2,2 \pm 0,1)$ e farinha de carne e ossos + farelo de soja $(2,1 \pm 0,1)$ (Lazzari et al. 2008), sendo que estes valores foram semelhantes aos encontrados neste trabalho.

A disponibilidade de juvenis em quantidade e qualidade é considerada um ponto crítico, para o sucesso da piscicultura, em que a nutrição é o principal fator responsável por erros frequentes em larvicultura, limitando a expansão da atividade (Prieto \& Atencio 2009). Com base nos resultados obtidos neste trabalho, verificou-se que a farinha de minhoca pode ser uma alternativa na composição de dietas para jundiá, na fase juvenil.

O pior desempenho dos jundiás, quando a inclusão de farinha de minhoca foi superior a $30 \%$, pode ser atribuído a fatores antinutricionais ou repelentes, que estão presentes na farinha de minhoca, podendo, inclusive, causar diminuição no consumo (Rotta et al. 2003). Outro fator que pode influenciar é a presença do líquido celomático da minhoca, já que Cardenete et al. (1993) demonstraram que a retirada deste, em dietas para truta arco-íris (Oncorhynchus mykiss), aumentou a palatabilidade da farinha de minhoca.

Outros fatores relacionados à baixa eficiência, em maiores níveis de farinha de minhoca, podem ser atribuídos ao desbalanceamento de aminoácidos ou ácidos graxos, devido ao alto nível de substituição. Outros fatores antinutricionais podem ser inerentes à farinha de minhoca, ou oriundos dos compostos que a minhoca degrada, que podem, também, conter metais pesados (Stafford \& Tacon 1984).

O farelo de crisálida é um subproduto da criação do bicho-da-seda (Bombyx mori), sendo que, assim como ocorre para a minhoca, a utilização de farinhas vem sendo pesquisada em dietas para animais. Para frangos de corte, ocorreu maior ganho de massa nos níveis de $50 \%$ de substituição da farinha de peixe por farinha de crisálidas, além de apresentar custo mais baixo (Dutta et al. 2012).

Para Trichogaster pectoralis, similarmente aos resultados observados neste trabalho, a farinha de crisálida em níveis mais altos apresentou problemas no desempenho da espécie, como baixa digestibilidade da proteína, o que ocasionou menores taxas de fecundidade (ovos peixe ${ }^{-1}$ ) e sobrevivência, quando o nível de inclusão foi de 100\% (Jintasataporn et al. 2011).

Outra fonte proteica oriunda de invertebrados estudada para a alimentação de peixes é a larva de mosca doméstica (Musca domesticus). Para o lambari bocarra (Oligusarcus argenteus), a utilização de 75\% de larva de mosca na ração proporcionou melhor rendimento de carcaça. O desempenho dos peixes não foi comprometido, quando se utilizou somente larva de mosca, em substituição a dietas comerciais, quando estas últimas são mais onerosas (Silva et al. 2009). Entretanto, antes de se utilizarem fontes alternativas, em estudos futuros, deve-se considerar questões de sanidade, fisiologia e definir os coeficientes de digestibilidade dos ingredientes.

Sabe-se que várias técnicas são utilizadas para a inativação de fatores antinutricionais, como o uso da atmosfera controlada, trituração, descortiçamento de grãos, tratamento enzimático, alta pressão isostática e, principalmente, o tratamento térmico, que é um método bastante utilizado para redução e/ou inativação de substâncias indesejáveis em alimentos (Benevides et al. 2011). Para tanto, é necessário, em trabalhos futuros, realizar estudos relacionados à composição bromatológica, processamento e conservação da farinha de minhoca, no sentido de inativar ou minimizar os compostos que possam vir a ser tóxicos aos animais, antes de utilizá-la na produção de dietas.

Observou-se efeito quadrático para o fator de condição ( $\mathrm{p}<0,01$, Figura 1$)$, no presente estudo. $\mathrm{O}$ fator de condição é um parâmetro que relaciona a massa com o comprimento do peixe, indicando sua estrutura corporal (Baldisserotto 2009).

Avaliando-se diferentes fontes proteicas para o jundiá, Lazzari et al. (2006) encontraram maior fator de condição em dietas contendo farinha de carne e ossos ou de peixe associado com farelo de soja.

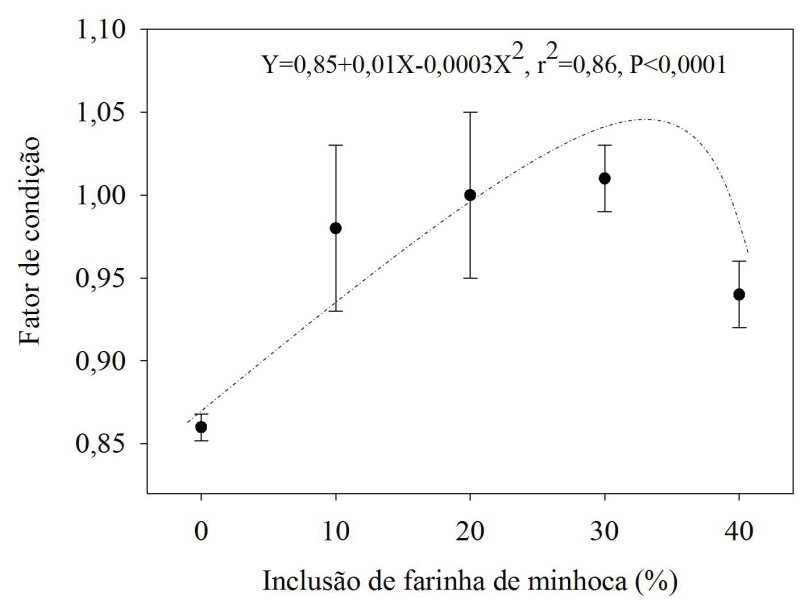

Figura 1. Fator de condição de jundiás submetidos a alimentação com diferentes níveis de farinha de minhoca na dieta (Palmeira das Missões, RS, 2011). 
Tabela 3. Valores de concentração de glicose e composição corporal de juvenis de jundiá submetidos a dietas com diferentes níveis de farinha de minhoca (Palmeira das Missões, RS, 2011).

\begin{tabular}{|c|c|c|c|c|c|c|}
\hline \multirow{2}{*}{ Variável } & \multicolumn{6}{|c|}{ Inclusão de farinha de minhoca (\%) } \\
\hline & 0 & 10 & 20 & 30 & 40 & $\mathrm{P}$ \\
\hline Glicose $\left(\mathrm{g} \mathrm{dL}^{-1}\right)$ & $23,66 \pm 9,2$ & $25,33 \pm 12,34$ & $19,66 \pm 7,1$ & $21,00 \pm 1,7$ & $32,33 \pm 5,5$ & $\mathrm{~ns}$ \\
\hline Cinzas $(\%)$ & $2,70 \pm 0,5$ & $2,18 \pm 0,3$ & $2,71 \pm 0,1$ & $2,54 \pm 0,1$ & $2,48 \pm 0,2$ & ns \\
\hline Umidade (\%) & $74,48 \pm 0,9$ & $75,45 \pm 0,5$ & $75,91 \pm 0,9$ & $76,34 \pm 0,9$ & $75,17 \pm 1,2$ & ns \\
\hline Lipídios (\%) & $7,51 \pm 0,7$ & $6,36 \pm 0,1$ & $6,70 \pm 0,7$ & $6,31 \pm 0,4$ & $6,25 \pm 0,5$ & ns \\
\hline Proteína $(\%)$ & $15,61 \pm 0,9$ & $16,20 \pm 0,6$ & $14,90 \pm 1,5$ & $16,07 \pm 1,3$ & $16,11 \pm 0,4$ & ns \\
\hline
\end{tabular}

Valores expressos como média \pm desvio padrão. ns: não significativo.

A associação das fontes proteicas, farelo de soja e levedura de cana também proporcionou maior fator de condição para esta espécie (Coldebella \& Radünz Neto 2002).

Nas análises de composição centesimal (cinzas, umidade, gordura e proteína) do peixe inteiro, não houve diferença significativa para a inclusão de farinha de minhoca nas dietas (Tabela 3 ).

Neste estudo, não houve efeito dos níveis de inclusão de farinha de minhoca na dieta sobre a glicose plasmática dos jundiás, indicando que os peixes não necessitaram mobilizar suas reservas energéticas.

O aumento dos níveis de glicose em peixes está relacionado a vários fatores, como variações na temperatura, transporte e manuseio (Acerete et al. 2004, Lermen et al. 2004, Urbinati et al. 2004). A mobilização de glicose tem por objetivo fornecer energia extra para o animal resistir a períodos de estresse (Chagas et al. 2007).

O jundiá é um peixe que, embora onívoro, possui exigências nutricionais similares às de um carnívoro. Altos níveis de glicose podem indicar uma dieta rica em carboidratos, o que pode promover redução na ingestão do alimento (glicemia elevada reduz o apetite) e, consequentemente, no crescimento dos animais (Baldisserotto 2009).

Evidenciou-se que a farinha de minhoca é uma boa opção para utilização em dietas de jundiá, pois não afetou a composição corporal dos peixes, quando comparada com a farinha de carne e ossos (controle). As taxas de deposição de proteína e gordura dependem muito da matéria-prima utilizada, que, no caso das farinhas de origem animal, possuem grande variação de composição (Lazzari et al. 2008). Porém, novos estudos visando a melhorar a qualidade do ingrediente são necessários para viabilizar um nível maior de inclusão da farinha de minhoca, sem promover diminuição no desempenho dos peixes.
É necessário, também, realizar um estudo de viabilidade econômica da utilização da farinha de minhoca, principalmente em fases de cultivo mais avançadas (crescimento e terminação), pois, atualmente, o custo deste ingrediente limita sua utilização.

\section{CONCLUSÃO}

A farinha de minhoca pode ser incluída em até $30 \%$, na dieta de juvenis de jundiá, sem comprometer o crescimento dos peixes.

\section{REFERÊNCIAS}

ACERETE, L. et al. Physiological responses in Eurasian perch (Perca fluviatilis L.) subjected to stress by transport and handling. Aquaculture, Amsterdam, v. 237, n. 1, p. 167-178, 2004.

ASSOCIATION OF OFFICIAL ANALYTICAL CHEMISTS (AOAC). Official methods of analysis of the Association of Official Analytical Chemists. 16. ed. Washington, DC: AOAC, 1995.

BALDISSEROTTO, B. Fisiologia de peixes. 2. ed. Santa Maria: UFSM, 2009.

BALDISSEROTTO, B.; RADÜNZ NETO, J.; BARCELlOS, L. G. Jundiá (Rhamdia sp.). In: BALDISSEROTTO, B.; GOMES, L. C. Espécies nativas para a piscicultura no Brasil. 2. ed. Santa Maria: UFSM, 2010. p. 301-323.

BENEVIDES, C. M. J. et al. Fatores antinutricionais em alimentos: revisão. Segurança Alimentar e Nutricional, Campinas, v. 18, n. 2, p. 67-79, 2011.

BLIGH, E. G.; DYER, W. J. A rapid method of total lipid extraction and purification. Canadian Journal of Biochemistry and Physiology, Ottawa, v. 37, n. 8, p. 911917, 1959.

BRASIL. Ministério da Pesca e Aquicultura. Boletim estatístico da pesca e aquicultura (Brasil 2010). 2012. Disponível em: <http://www.mpa.gov.br/ 
images/Docs/ Informacoes_e_Estatisticas/Boletim $\% 20$ Estat $\%$ C3\%ADstico\%20MPA $\% 202010$.pdf>. Acesso em: 30 nov. 2012.

CARDENETE, G. et al. Nutritive utilization of earthworm protein by fingerling rainbow trout (Onchrhynchus mykiss). In: KANSHIK, S. J.; LUQUET, P. Fish nutrition in practice. Paris: Institut National de la Recherche Agronomique, 1993. p. 923-926.

CHAGAS, E. C. et al. Produtividade de tambaqui criado em tanque-rede com diferentes taxas de alimentação. Ciência Rural, Santa Maria, v. 37, n. 4, p. 1109-1115, 2007.

COLDEBELLA, I. J.; RADÜNZ NETO, J. Farelo de soja na alimentação de alevinos de jundiá (Rhamdia quelen). Ciência Rural, Santa Maria, v. 32, n. 3, p. 499-503, 2002.

DUTTA, A.; DUTTA, S.; KUMARI, S. Growth of poultry chicks fed on formulated feed containing silk worm pupae meal as protein supplement and commercial diet. Journal of Animal and Feed Research, Aziziye, v. 2, n. 3, p. 303307, 2012.

FERRUZZI, C. Manual de lombricultura. Madrid: MundiPrensa, 2001.

FRACALOSSI, D. M. et al. Desempenho do jundiá, Rhamdia quelen, e do dourado, Salminus brasiliensis, em viveiros de terra na região Sul do Brasil. Acta Scientiarum, Maringá, v. 26, n. 3, p. 345-352, 2004.

GALDIOLI, E. M. et al. Diferentes fontes proteicas na alimentação de alevinos de curimba (Prochilodus lineatus). Acta Scientiarum, Maringá, v. 22, n. 2, p. 471477, 2000.

J IN TA S ATAPORN, O.; CHUMKAM, S.; JINTASATAPORN, O. Substitution of silkworm pupae (Bombyx mori) for fish meal in broodstock diets for snakeskin Gourami (Trichogaster pectoralis). Journal of Agricultural Science and Technology, Tehran, v. 1, n. 8, p. 1341-1344, 2011.

LAZZARI, R. et al. Diferentes fontes proteicas para a alimentação do jundiá (Rhamdia quelen). Ciência Rural, Santa Maria, v. 36, n. 1, p. 240-246, 2006.

LAZZARI, R. et. al. Desempenho e composição dos filés de jundiás (Rhamdia quelen) submetidos a diferentes dietas na fase de recria. Arquivo Brasileiro de Medicina Veterinária e Zootecnia, Belo Horizonte, v. 60, n. 2, p. 477-484, 2008.

LERMEN, C. L. et al. Effect of different temperature regimes on metabolic and blood parameters of silver catfish Rhamdia quelen. Aquaculture, Amsterdam, v. 239, n. 4, p. 497-507, 2004.

MILLAMENA, O. M. Replacement of fish meal by animal byproduct meals in a practical diet for grow-out culture of grouper Epinephelus coiodes. Aquaculture, Amsterdam, v. 204, n. 1, p. 75-84, 2002.
OLELE, N. F. Growth response of Heteroclarias fingerlings fed on earthworm meal in hatchery tanks. Life Science Journal, Delhi, v. 3, n. 2, p. 131-136, 2011.

PEZZATO, L. E. et. al. Digestibilidade aparente de ingredientes pela tilápia do Nilo (Oreochromis niloticus). Revista Brasileira de Zootecnia, Viçosa, v. 31, n. 4, p. 1595-1604, 2002.

PRIETO, M.; ATENCIO, V. Zooplancton en la larvicultura de peces neotropicales. Revista MVZ Córdoba, Córdoba, v. 13, n. 2, p. 1415-1425, 2009.

RAWLING, M. D. et al. Haemato-immunological and growth response of mirror carp (Cyprinus carpio) fed a tropical earthworm meal in experimental diets. Fish \& Shellfish Immunology, Tokyo, v. 32, n. 6, p. 1002-1007, 2012.

ROSTAGNO, S. et al. Tabelas brasileiras para aves e suínos: composição de alimentos e exigências nutricionais. 3. ed. Viçosa: UFV, 2011.

ROTTA, M. A. et al. Uso da farinha de minhoca como alimento para pós-larvas de tilápia. Corumbá: Embrapa Pantanal, 2003. (Boletim de pesquisa e desenvolvimento, 45).

SILVA, R. F. et. al. Larva de mosca doméstica como alternativa na alimentação de lambari bocarra (Oligusarcus argenteus). Zootecnia Tropical, Maracay, v. 27, n. 3, p. 329-334, 2009.

SOGBESAN, A. O.; MADU, C. T. Evaluation of earthworm (Hyperiodillus euryaulos, clausen, 1914; oligocheata: eudrilidae) meal as protein feedstuffs in diet for Heterobranchus longifilis valenciennes, 1840 (teleostei, clariidae) fingerlings under laboratory condition. Research Journal of Environmental Sciences, New York, v. 2, n. 1, p. 23-31, 2008.

SOUZA, R. S. et al. Diferentes fontes proteicas de origem vegetal para tilápia do Nilo (Oreochromis niloticus L.) durante a reversão sexual. Acta Scientiarum Animal Sciences, Maringá, v. 26, n. 1, p. 21-28, 2004.

SOUZA, R. S. et. al. Desempenho zootécnico e econômico de juvenis de robalo-peva alimentados com dietas contendo diferentes concentrações proteicas. Pesquisa Agropecuária Brasileira, Brasília, DF, v. 46, n. 2, p. 190-195, 2011.

STAFFORD, E. A.; TACON, A. G. J. Nutritive value of the earthworm, Dendrodrilus subrubicundus, growth on domestic sewage, in trout diets. Agricultural Wastes, Aubiére, v. 9, n. 2, p. 249-266, 1984.

UNITED STATES OF AMERICA (USA). National Research Council. Nutrient requirements of fish and shrimp. Washington, DC: The National Academic Press, 2011.

URBINATI, E. C. et al. Loading and transport stress in juvenile matrinxã (Brycon cephalus) at various densities. Aquaculture, Amsterdam, v. 229, n. 1, p. 389-400, 2004. 